\title{
ANALISIS "RANGKAIAN TAHAPAN OPERASIONAL" PEMBUATAN BELIUNG BATU DARI PERBENGKELAN NEOLITIK DI BANYUWANGI SELATAN
}

\author{
“CHAÎNE OPÉRATOIRE” ANALYSIS OF STONE ADZE \\ FROM NEOLITHIC WORKSHOP IN SOUTH BANYUWANGI
}

\author{
Sofwan Noerwidi \\ Balai Arkeologi Yogyakarta \\ noerwidi@arkeologijawa.com
}

\begin{abstract}
Prehistoric research in South Banyuwangi by the National Center of Archaeology of Yogyakarta Regional Office between 2008-2011 have found artifact assemblage which indicating stone tool workshop activities. The typology of artifacts which reflecting workshop activities, including; nucleus, percutor, debitage, rough adze, and polishing stone. This paper uses chaîne opératoire approach to reconstruct the producing process and technological aspects related to the manufacturing process of stone adze from neolithic workshop sites in the region. This study is expected to increasing our understanding on technological perspective in the manufacture of Neolithic stone tools, and to give some idea about the social aspects of life of Austronesian speaking people in Indonesia.
\end{abstract}

Keywords: Chaîne Opératoire, Neolithic, Adze, Banyuwangi.

\begin{abstract}
ABSTRAK
Berdasarkan hasil penelitian Balai Arkeologi Yogyakarta antara tahun 2008-2011, di kawasan Banyuwangi Selatan telah ditemukan kumpulan artefak yang mengindikasikan adanya aktivitas perbengkelan alat batu. Jenis artefak yang mencerminkan pola tingkah lalu tersebut antara lain adalah; batu inti, batu pukul, tatal, calon beliung, dan batu asah. Tulisan ini menggunakan pendekatan chaîne opératoire untuk merekonstruksi proses pembuatan dan mengungkap aspek-aspek teknologi yang berkaitan dengan proses pembuatan beliung batu dari situs-situs perbengkelan neolitik di kawasan tersebut. Studi ini diharapkan mampu menambah pandangan mengenai teknologi pembuatan alat batu pada masa neolitik dan sedikit gambaran tentang aspek sosial kehidupan masyarakat penutur bahasa Austronesia di Indonesia.
\end{abstract}

Kata kunci: Chaîne Opératoire, Neolitik, Beliung, Banyuwangi 


\section{PENDAHULUAN}

Salah satu produk budaya yang khas dari periode Neolitik di Kepulauan Indonesia adalah beliung batu yang diupam, baik yang berpenampang persegi maupun membulat. Kehadiran teknologi pembuatan beliung persegi di kepulauan ini sering dihubungkan dengan kehadiran masyarakat petani peladang tradisional penutur bahasa Austronesia. Bellwood (2000) mengajukan teori bahwa masyarakat Austronesia berekspansi dari Asia Daratan menuju Asia Tenggara Kepulauan membawa pola subsistensi pertanian, namun masih memiliki kemahiran berburu dan mengumpulkan makanan baik di darat maupun di laut. Mereka memperkenalkan teknologi baru yaitu teknologi tembikar dan alat batu berupa beliung batu bertajaman satu sisi yang diupam (Bellwood 2000, 299). Berdasarkan bukti arkeologi, situs masa neolitik yang paling awal di kawasan Asia Tenggara adalah situs-situs budaya Tapenkeng di Taiwan (5000 BP). Selain itu, di Taiwan pada masa yang hampir bersamaan juga berkembang dua kompleks budaya neolitik lainnya, yaitu budaya Yuanshan dan budaya Peinan (4000-5000 BP) (Spriggs 2000, 62).

Ciri khas utama kompleks budaya neolitik di Taiwan adalah; beliung persegi, mata panah dari tulang dan batu sabak, serta tradisi tembikar yang cenderung berkembang dari dominasi tembikar berhias pola tera tali menuju tembikar polos atau berpoles merah (pada kasus budaya Yuanshan dan Peinan), sementara tembikar dengan motif hias gores, tera bulatan dan tusukan, serta kaki melingkar berlubang terus berlanjut. Artefak lainnya adalah bandul pemberat jaring dari batu, cangkul batu, alat pemukul kulit kayu, aksesoris (manik-manik dan gelang) dari cangkang kerang, beliung dan kail dari cangkang kerang, alat memanen padi (ani-ani) dan kumparan tenun dari tanah liat. Selain itu, ciri kompleks budaya Austronesia lainnya yang dibawa serta pada saat mereka berekspansi adalah; domestikasi babi, anjing, ayam, dan kadang-kadang ikut terangkut juga tikus besar (Bellwood 2000, 321-322; Spriggs 1989, 587; dan Spriggs 2000, 62-63).

Di kepulauan Indonesia, Heekeren (1974) telah mencatat lokasi persebaran berbagai macam tipologi beliung batu, seperti misalnya; pesisir pantai barat, Bengkulu, Palembang, Lampung dan Assam di Sumatra, Banten, Kelapa Dua, Pejaten, Kampung Keramat, dan Buni (Jakarta dan Tangerang), Pasir Kuda di Bogor, Cibadak, Cirebon, Tasikmalaya di Priangan, Pekalongan, Gunung Karangbolang di Banyumas, Semarang, Yogyakarta, Punung dan Wonogiri, Madiun, Surabaya, Madura, Malang, Kendeng Lembu dan Pager Gunung (Besuki) di Jawa, Tondano, Minahasa, Sungai Sario di Manado, Bulukumba, Sempaga, Kalumpang dan Minanga Sipakko di Sulawesi Barat, Dumahang di Sangir, Ennawira, Rainis, dan Essang di Talaud, serta di Bali, Flores, Adonara, Leti, Tanimbar, Maluku, Solor, dan Kalimantan (Heekeren 1974, 168-170; Soejono 1984). Secara ringkas, di Indonesia bagian barat pada umumnya didominasi oleh beliung persegi, sedangkan di Indonesia bagian timur kebanyakan kapak lonjong.

Studi mengenai teknologi pembuatan beliung batu di Indonesia, khususnya di Jawa telah dilakukan oleh Simanjuntak (1984) pada situs perbengkelan Tipar-Ponjen, Purbalingga, kemudian Muhammad Heydar (1989), Daud Aris Tanudirjo (1991), Nugroho Widi Hantoro (1995), dan Harry Widianto (1998) pada situs-situs perbengkelan di Punung, Pacitan. Tulisan ini bertujuan untuk mengungkap aspek-aspek teknologi yang berkaitan dengan proses pembuatan beliung batu dari situs-situs perbengkelan Neolitik di kawasan Banyuwangi Selatan. Studi ini diharapkan dapat menambah perspektif mengenai teknologi pembuatan alat batu pada masa neolitik dan sedikit gambaran tentang kehidupan masyarakat penutur bahasa Austronesia di Indonesia.

\section{METODE PENELITIAN}

Perlu disadari bahwa data
arkeologi bersifat tidak lengkap
(fragmentary), terbatas (finite), dan khas 
(contextual) (Tanudirjo 2003). Oleh karena itu, segala upaya untuk membangun pengetahuan tentang masa lampau harus mempertimbangkan faktorfaktor tersebut serta menggunakan analisis yang tepat. Kondisi data arkeologi yang unik tersebut mungkin sejalan dengan konsep transformasi data yang dipopulerkan oleh Schiffer (1976). Ada dua konteks utama yang dapat menjelaskan keberadaan data arkeologi, yaitu konteks sistem dan konteks arkeologi. Konteks sistem, adalah lingkungan budaya yang masih berlangsung. Dalam konteks ini, data arkeologi masih berperan aktif dan digunakan oleh masyarakat pendukungnya. Konteks arkeologi, adalah lingkungan tempat data arkeologi sudah tidak digunakan lagi oleh masyarakat pendukungnya. Data arkeologi yang tidak digunakan ini seringkali menjadi rusak, hilang dan punah. Namun, tidak jarang data arkeologi ini masih ada namun tidak tampak, tercerai-berai, fragmentaris, dan masih mungkin untuk ditemukan kembali (Schiffer 1976).

$$
\text { Studi mengenai proses }
$$

transformasi alat batu sebagai salah satu produk data arkeologi telah memiliki sejarah yang cukup panjang. Sejak awal kemunculan arkeologi paleolitik di Eropa Barat, proses pembuatan alat batu mendapatkan perhatian yang spesial. Berbagai studi dilakukan bertujuan untuk melakukan tipologi secara sistematis artefak batu berdasarkan deskripsi fitur teknologi dan atribut morfologi. Akhirnya, konsep chaîne opératoire, atau "operational sequence" (kadang digunakan istilah "core reduction sequence"), yang dipinjam dari bahasa Perancis, telah diperkenalkan dalam studi prasejarah di dunia lama. Kerangka konseptual chaîne opératoire difokuskan pada pemahaman keseluruhan teknologi dan skil praktis si pembuat alat batu (prehistoric knapper) dalam penggunaan teknik yang khas untuk mentransformasi bahan baku (raw material) menjadi alat batu (stone tools) (Bar-Yosef \& van Peer 2009).

Chaîne opératoire (bahasa Perancis untuk "rangkaian operasional") atau operational sequences adalah istilah yang digunakan dalam antropologi, tetapi lebih umum digunakan dalam studi arkeologi. Pendekatan ini berfungsi sebagai alat metodologis untuk menganalisis proses teknis dan tindakan sosial yang terlibat dalam suatu proses produksi seperti alat batu atau tembikar, baik langkahlangkahnya, penggunaan, hingga pembuangan akhir artefak tersebut (Grace 1997). Konsep teknologi sebagai studi pola tingkah laku manusia ini pertama kali diusulkan oleh arkeolog Perancis, André Leroi-Gourhan, dan kemudian dipopulerkan oleh AndréGeorges Haudricourt. Keduanya adalah murid Marcel Mauss yang sebelumnya mengakui bahwa masyarakat masa lampau bisa dipahami melalui teknologi berdasarkan fakta chaîne opératoire yang merupakan langkah-langkah teratur sesuai dengan logika internal khusus dalam masyarakat yang bersangkutan (Soressi dan Geneste 2011).

Definisi umum chaîne opératoire adalah studi mengenai proses produksi alat batu. Chaîne opératoire dapat meliputi studi teknik pemukulan (percussion), analisis tatal (débitage) dan elemen non retus lainnya dalam sebuah assemblage, serta identifikasi fungsi dari alat batu. Dalam skala tersebut, prosedur dalam proses produksi alat batu menjadi identik pendekatan chaîne opératoire, dan penggunaan istilah tersebut dalam studi prasejarah dikenal sebagai kontribusi aliran "French School" dalam arkeologi (Bar-Yosef dan van Peer 2009). Dalam bahasa Indonesia, istilah chaîne opératoire diterjemahkan menjadi "rangkaian tahapan operasional" yang dilalui dalam proses pembuatan alat. Proses ini dimulai dari tahap pencarian, perolehan, dan pemilihan bahan baku; diikuti dengan penyiapan dan pengerjaan bahan dengan penerapan teknik-teknik pemangkasan dan peretusan sesuai dengan konsep si pembuat; hingga alat yang diinginkan dihasilkan. (Simanjuntak 2007). Chaîne opératoire muncul dari kebutuhan untuk menggambarkan metodologi analisis litik dalam studi arkeologi. Hal tersebut 
memungkinkan para arkeolog untuk merekonstruksi urutan kronologis dan teknik yang digunakan, serta berbagai langkah yang dilakukan untuk menghasilkan sebuah artefak. Analisis artefaktual telah mengalami beberapa perubahan sepanjang sejarahnya, bergeser orientasi yang awalnya merupakan bagian dari ilmu alam dalam prasejarah manusia, menjadi bagian dalam antropologi sosial budaya, kaitannya dengan teknik produksi dalam masyarakat prasejarah (Soressi \& Geneste 2011).

Berdasarkan sudut pandang tersebut, sebuah chaîne opératoire dapat dipahami sebagai produk sosial, karena penggunaan pendekatan interdisipliner untuk analisis artefak yang mengintegrasikan beberapa subdisiplin antropologi yaitu: arkeologi, antropologi sosial-budaya, antropologi biologi, dan antropologi linguistik. Sehingga chaîne opératoire menawarkan perspektif multidimensi masyarakat prasejarah, dan menunjukkan bahwa pendekatan tersebut tidak dapat bekerja secara independen dalam masyarakat pendukungnya. Akibatnya, studi teknologi pembuatan artefak atau chaîne opératoire memungkinkan untuk lebih memahami tidak hanya masyarakat sang pemilik teknologi, tetapi juga konteks sosial, pola tingkah laku, dan aspek kognisi yang melatarbelakangi produksi suatu artefak (Soressi \& Geneste 2011).

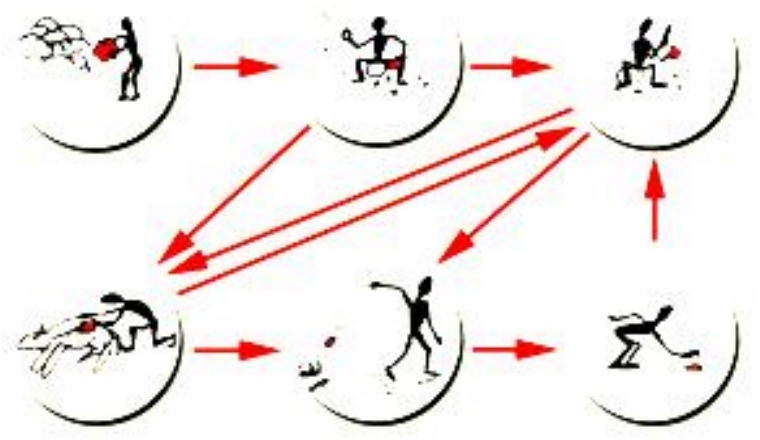

Gambar 1. Diagram Chaîne Opératoire Alat Batu pada M asa Prasejarah

(Sumber: www.wikipedia.org)

Tulisan ini akan membahas aspekaspek teknologi yang berkaitan dengan proses pembuatan beliung batu dari situs-situs perbengkelan Neolitik di kawasan Banyuwangi Selatan. Tulisan ini tidak banyak membahas aspek sosial budaya masyarakat pendukung budaya neolitik di kawasan tersebut, disebabkan oleh kondisi data arkeologis yang sangat fragmentaris. Bahan analisis dalam tulisan ini adalah artefak alat-alat batu hasil penelitian yang telah dilakukan oleh Balai Arkeologi Yogyakarta di kawasan Banyuwangi Selatan antara tahun 20082011. Penelitian tersebut antara lain adalah :

1. Ekskavasi Situs Kendenglembu dan Rejosari tahun 2008

2. Survei kawasan Kendenglembu dan sekitarnya tahun 2008

3. Survei kawasan pesisir Banyuwangi Selatan tahun 2009

4. Ekskavasi Situs Rejosari tahun 2010

5. Ekskavasi Situs Panuwunmukti dan Kendenglembu tahun 2011

Analisis artefak hasil dari dua tipe penelitian itu tidak dipisahkan karena berdasarkan hasil ekskavasi diketahui bahwa di kawasan tersebut terdapat hanya ada satu fase budaya neolitik. Selain itu, kebanyakan dari situs permukiman-perbengkelan tersebut adalah situs terbuka (open site) yang kebanyakan telah terganggu oleh aktifitas pengolahan tanah untuk perkebunan karet, coklat, kopi, jati, dan kayu industri lainnya. Pada kenyataannya, dalam proses penyiapan lahan untuk perkebunan-perkebunan tersebut dilakukan pengolahan tanah menggunakan bajak hingga di kedalaman $50 \mathrm{~cm}$. Sehingga artefak dengan karakter budaya neolitik yang didapat berdasarkan survei permukaan, juga dianggap berasal dari fase budaya neolitik yang ditemukan dalam ekskavasi arkeologis.

\section{CHAINE OPERATOIRE BELIUNG DARI BANYUWANGI SELATAN}

Beberapa tahapan utama dalam chaîne opératoire yang berkenaan dengan proses transformasi suatu alat batu dalam konteks sistem adalah ; proses pencarian bahan baku, proses buat, proses pakai, dan proses buang. Sedangkan aspek-aspek yang perlu 
diperhatikan dalam tiap tahapan dalam chaîne opératoire adalah ; bahan baku, artefak pembuat, teknik pembuatan, dan artefak yang dihasilkan. Berikut ini adalah pembahasan dari tiap aspek dalam chaîne opératoire yang menyangkut pola aktivitas perbengkelan beliung batu di kawasan Banyuwangi Selatan, yaitu :

\section{Bahan Baku}

Bahan baku yang dipilih untuk pembuatan beliung batu di Banyuwangi Selatan adalah batu lempung silikaan berwarna abu kehijauan dan coklat. Kriteria pemilihan bahan baku ini didasarkan pada: tingkat kekerasan, sifat mudah terbelah, kehomogenan komposisi batuan. Berdasarkan hasil analisis oleh Noerwidi (2013) mengenai cakupan situs-situs neolitik di Banyuwangi Selatan dalam hubungannya dengan distribusi sumber bahan litik, diketahui bahwa situs tersebut lokasinya relatif dekat dengan banyak sumber bahan baku litik untuk pembuatan beliung batu.
Bahan baku batu lempung silikaan di kawasan Banyuwangi Selatan dapat dijumpai di Sungai Sawojajar di Kampung Anyar, Gunung Lembu, Sungai Lele, Bukit Senepo, Gunung Tembakur, Gunung Lampong dan Gunung Gendang. Berdasarkan hasil penelitian tersebut dapat diketahui bahwa jarak rata-rata antara situs permukiman dengan lokasi sumber bahan adalah 1 hingga $5 \mathrm{Km}$. Bahkan tiga situs di daerah Senepo, di tepi Kali Baru tepat berada pada lokasi singkapan batu lempung silikaan. Jarak tersebut relatif cukup dekat bagi masyarakat neolitik yang telah tinggal menetap di situs permukiman terbuka. Jarak 1 hingga $5 \mathrm{Km}$ tentunya dapat dijangkau dengan perjalanan 1 hari pulang pergi, untuk mendapatkan bahan baku alat litik yang pada umumnya terletak pada singkapan di dinding tebing perbukitan di Kompleks Pegunungan Merawan (Noerwidi 2013).

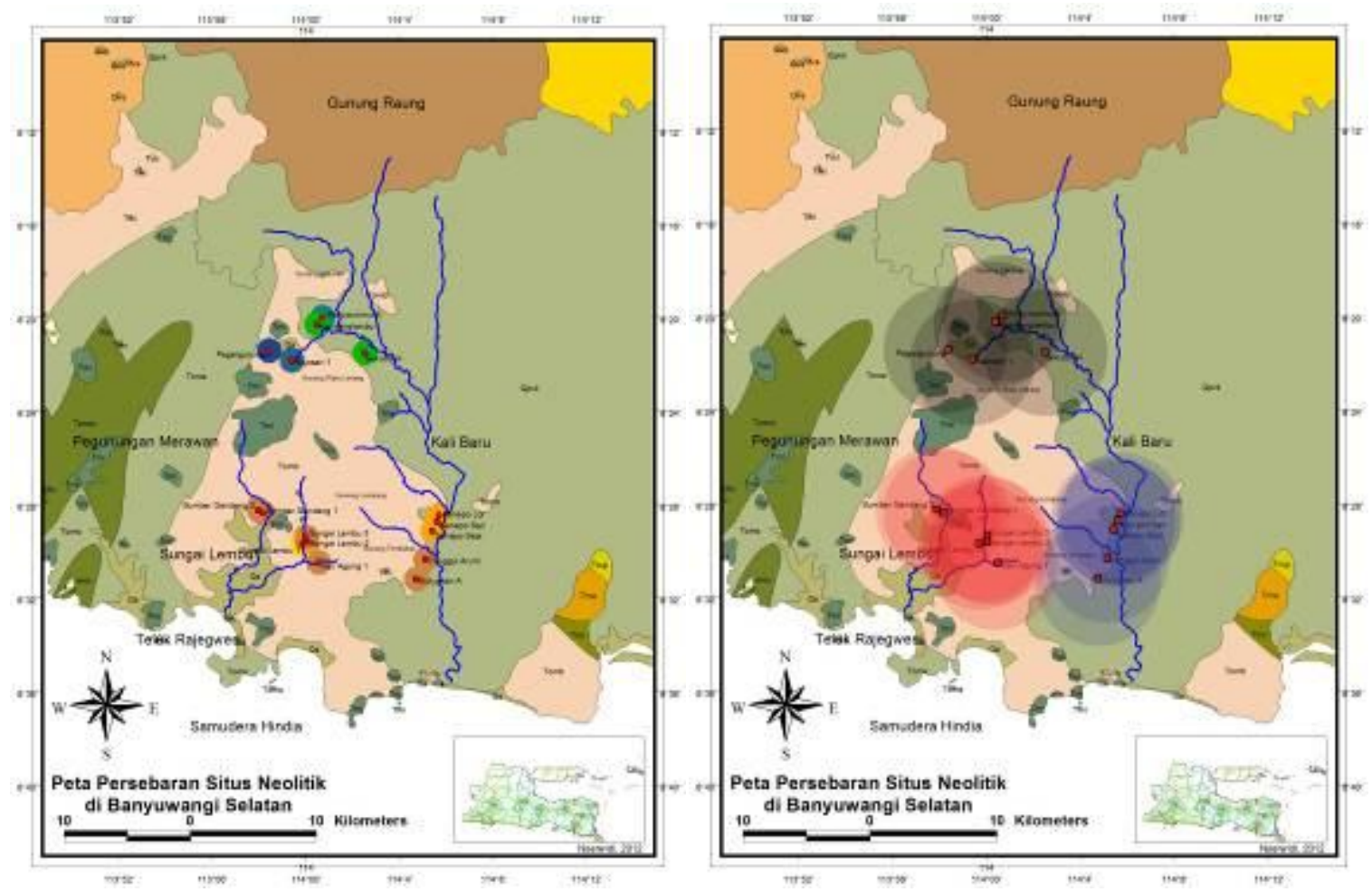

Peta 1. Peta Hipotesis Zona Cakupan Situs-situs Neolitik di Banyuwangi Selatan Hubungannya dengan Geologi, Radius Inti 1 Km (Kiri) dan Radius Primer 5 Km (Kanan)

(Sumber: Noerwidi 2013) 
Selain itu, berdasarkan hasil pengamatan berbagai bahan baku artefak litik dari penelitian Situs Rejosari tahun 2008 dan Sukobumi tahun 2010 terdapat material batu lempung silikaan abu-abu kehijauan, dan sebagian kecil artefak litik lainnya terbuat dari batu lempung silikaan coklat. Berdasarkan hasil survei permukaan Balai Arkeologi Yogyakarta tahun 2008 di sekitar kawasan aliran Sungai Kalibaru, dapat diketahui bahwa singkapan formasi batu lempung silikaan yang paling dekat dengan keberadaan Situs Rejosari dan Sukobumi adalah di Gunung Lembu yang berjarak sekitar $2 \mathrm{Km}$ di sebelah barat daya Situs Sukobumi. Sedangkan lokasi sumber bahan artefak litik batu rijang coklat dari kedua situs tersebut kemungkinan berasal dari Situs Seneposari yang berjarak sekitar $12 \mathrm{~km}$ di sebelah selatannya.

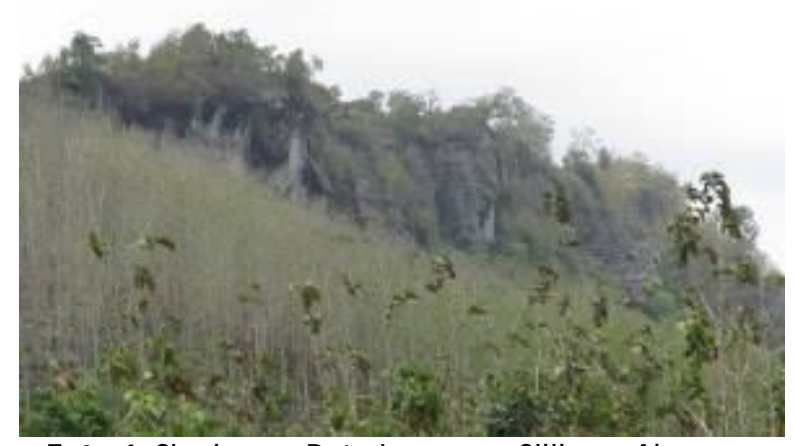

Foto 1. Singkapan Batu Lempung Silikaan Abuabu kehijauan di Pegunungan Merawan

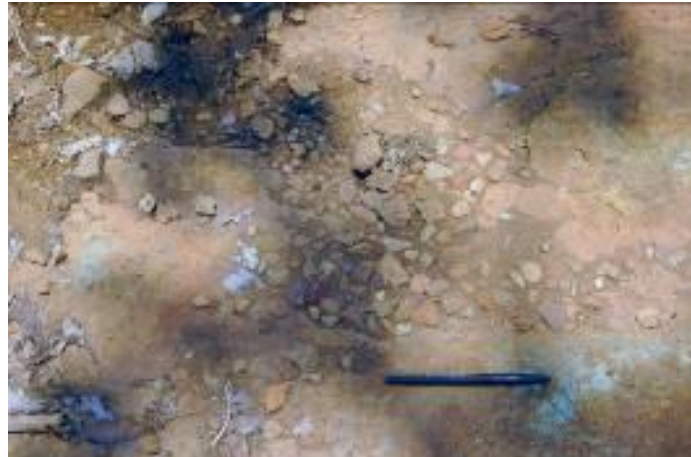

Foto 2. Singkapan Batu Lempung Silikaan Coklat serta Sebaran Tatal di Situs Seneposari.

(Sumber: Tim Penelitian 2008)

\section{Produk Artefak}

\section{Batu Inti}

Temuan batu inti merupakan bongkahan batu yang merupakan bahan baku untuk pembuatan alat batu. Bongkahan batu ini telah diserpih pada bagian dataran pukul sebagai persiapan untuk penyerpihan selanjutnya. Pada penelitian tahun 2008-2009 telah ditemukan sembilan buah batu inti dari delapan situs, yang berasal dari bahan baku batulempung abu-abu kehijauan kuning kecoklatan. Berdasarkan hasil pengukuran, dapat diketahui bahwa seluruh batu inti tersebut memiliki berat kurang dari 1000 gr, sehingga diperkirakan bahwa artefak tersebut disiapkan dan dibentuk di lokasi penambangan untuk kemudian didistribusikan kepada situs-situs konsumen dalam ukuran yang mudah untuk dibawa.

Tabel 1. Temuan batu inti dari situs-situs di Banyuwangi Selatan

\begin{tabular}{|c|l|l|c|l|}
\hline No. & \multicolumn{1}{|c|}{ Situs } & \multicolumn{1}{|c|}{ Bahan } & Berat (gr) & \multicolumn{1}{c|}{ Jejak Teknologi } \\
\hline 1 & Kendenglembu & $\begin{array}{l}\text { Batulempung Abu-abu } \\
\text { Kehijauan }\end{array}$ & 900 & $\begin{array}{l}\text { Terpangkas pada bagian } \\
\text { lateral }\end{array}$ \\
\hline 2 & Panuwunmukti & $\begin{array}{l}\text { Batulempung Abu-abu } \\
\text { Kehijauan }\end{array}$ & 522,8 & $\begin{array}{l}\text { Terpangkas di kedua sisi } \\
\text { lateral }\end{array}$ \\
\hline 3 & Panuwunmukti & $\begin{array}{l}\text { Batulempung Kuning } \\
\text { Kecoklatan }\end{array}$ & 303,7 & Terpangkas satu sisi lateral \\
\hline 4 & Panuwunmukti & $\begin{array}{l}\text { Batulempung Abu-abu } \\
\text { Kehijauan }\end{array}$ & 950,2 & $\begin{array}{l}\text { Terdapat jejak sawing pada } \\
\text { sisi lateral }\end{array}$ \\
\hline 5 & Seneposari & $\begin{array}{l}\text { Batulempung Kuning } \\
\text { Kecoklatan }\end{array}$ & 343,3 & Terdapat jejak pemangkasan \\
\hline 6 & Seneposari & $\begin{array}{l}\text { Batulempung Abu-abu } \\
\text { Kehijauan }\end{array}$ & 445,7 & $\begin{array}{l}\text { Terdapat jejak sawing pada } \\
\text { sisi dorsal dan ventral }\end{array}$ \\
\hline
\end{tabular}




\begin{tabular}{|c|l|l|c|l|}
\hline 7 & Rejosari 1 & $\begin{array}{l}\text { Batulempung Abu-abu } \\
\text { Kehijauan }\end{array}$ & 220 & $\begin{array}{l}\text { Terdapat jejak sawing pada } \\
\text { dua sisi lateral }\end{array}$ \\
\hline 8 & Sungailembu 2 & $\begin{array}{l}\text { Batulempung Abu-abu } \\
\text { Kehijauan }\end{array}$ & 588,7 & $\begin{array}{l}\text { Terpangkas di kedua sisi } \\
\text { lateral }\end{array}$ \\
\hline 9 & Sungailembu 4 & $\begin{array}{l}\text { Batulempung Abu-abu } \\
\text { Kehijauan }\end{array}$ & 800,2 & Terpangkas satu sisi lateral \\
\hline
\end{tabular}

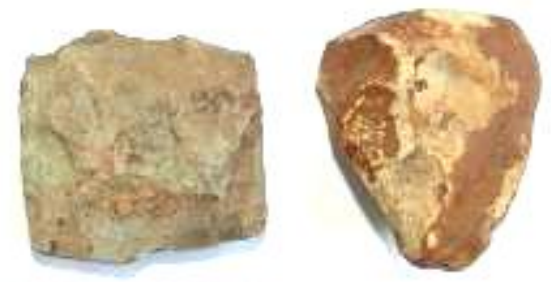

Foto 3. Dua M acam Bahan Baku Batu Inti dari Situs Rejosari 1 di Treblasala.

(Sumber: Tim Penelitian 2008)

Tatal

Tatal merupakan limbah artefak batu yang dihasilkan pada saat proses penyerpihan, dalam pembuatan bentuk dasar beliung. Berdasarkan ukuran dan atribut teknologinya, secara garis besar ada tiga tipe tatal yang dihasilkan dari tiap tahapan pembuatan beliung, yaitu :
1. Tatal besar $(>5 \mathrm{~cm})$, dihasilkan oleh tahap pemangkasan langsung dan pembentukan awal

2. Tatal sedang $(3-5 \mathrm{~cm})$, dihasilkan oleh tahap pemangkasan tidak langsung dan bentuk dasar beliung

3. Tatal kecil $(<3 \mathrm{~cm})$, dihasilkan oleh tahap pemangkasan tidak langsung dan tahap pemangkasan detail bentuk dasar beliung

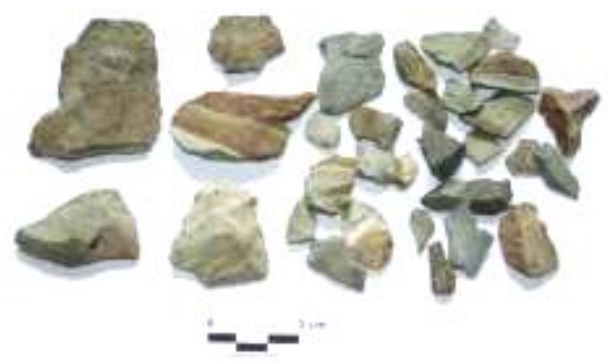

Foto 4. Tatal Besar, Sedang, dan Kecil dari Situs Sukobumi. (Sumber: Tim Penelitian 2010)

\section{Fragmen Calon Beliung}

Fragmen calon beliung merupakan artefak yang dihasilkan karena kegagalan dalam proses pembuatan beliung batu. Berdasarkan kegagalan dalam tahapan proses pembuatannya, ada beberapa jenis fragmen calon beliung khususnya yang ditemukan di Situs Sukobumi dan Situs Panuwunmukti, antara lain adalah:

1. Fragmen calon beliung dari tahap pemotongan (sawing) bentuk dasar

2. Fragmen calon beliung dari tahap pemangkasan detail calon beliung
3. Fragmen calon beliung dari tahap pengupaman calon beliung

\section{Calon Beliung}

Calon beliung atau Plank (Rough Adze) adalah hasil penyerpihan batu inti yang telah berbentuk persegi sebagai bentuk dasar beliung. Pada calon beliung, jejak penyerpihan sebagian besar masih nampak pada bagian permukaan sehingga bentuknya relatif masih kasar. Selain itu, bidang tajaman calon beliung juga belum dibentuk. Temuan paling banyak dihasilkan dari 
situs Panuwunmukti, menemukan sepuluh buah calon beliung. Sembilan buah calon beliung dibuat dari bahan batulempung silikaan abu-abu kehijauan dan sebuah lainnya dari batulempung silikaan coklat kekuningan.
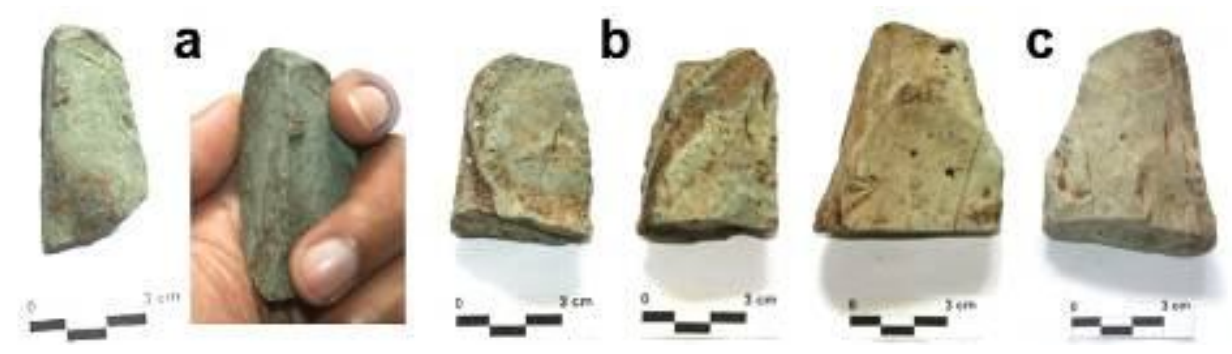

Gambar 2. Fragmen calon beliung dari tahap (a) pemotongan (sawing) bentuk dasar, (b) tahap pemangkasan detail calon beliung, (c) tahap pengupaman calon beliung.

(Sumber: Tim Penelitian 2011)

Tabel 2. Temuan Calon Beliung dari situs-situs di Banyuwangi Selatan

\begin{tabular}{|c|l|l|c|l|}
\hline No. & \multicolumn{1}{|c|}{ Situs } & \multicolumn{1}{|c|}{ Tipologi } & Ukuran $\mathbf{( c m})$ & \multicolumn{1}{|c|}{ Jejak Teknologi } \\
\hline 1 & Kendenglembu & Calon Beliung & $7,5 \times 3 \times 2$ & $\begin{array}{l}\text { Sawing dan Knapping } \\
\text { tahap lanjut }\end{array}$ \\
\hline 2 & Panuwunmukti & Calon Kapak Tembeling & $15 \times 8,5 \times 3,5$ & Knapping tahap awal \\
\hline 3 & Panuwunmukti & Calon Pahat & $11 \times 2,5 \times 2$ & Sawing \\
\hline 4 & Panuwunmukti & Calon Beliung & $13 \times 6 \times 2,5$ & $\begin{array}{l}\text { Sawing di bagian proximal } \\
\text { dan knapping detail di } \\
\text { bagian lateral }\end{array}$ \\
\hline 5 & Panuwunmukti & Calon Beliung & $12 \times 5,5 \times 2,5$ & Knapping tahap awal \\
\hline 6 & Panuwunmukti & Calon Pahat & $15 \times 3,5 \times 2,5$ & Knapping tahap awal \\
\hline 7 & Panuwunmukti & Calon Beliung & $13 \times 5 \times 2,5$ & $\begin{array}{l}\text { Sawing di bagian lateral } \\
\text { dan Knapping tahap awal }\end{array}$ \\
\hline 8 & Panuwunmukti & Calon Beliung & $11 \times 4,5 \times 2,5$ & $\begin{array}{l}\text { Sawing di bagian proximal } \\
\text { dan Knapping tahap awal }\end{array}$ \\
\hline 9 & Panuwunmukti & Calon Beliung & $10 \times 4,5 \times 2,5$ & Knapping tahap awal \\
\hline 10 & Panuwunmukti & Calon Beliung & $9,5 \times 4,5 \times 2$ & $\begin{array}{l}\text { Sawing di bagian proximal } \\
\text { dan lateral serta Knapping } \\
\text { tahap awal }\end{array}$ \\
\hline 11 & Panuwunmukti & Calon Beliung & $9 \times 5 \times 2,5$ & Knapping tahap awal \\
\hline 12 & Panuwunmukti & Calon Beliung & $7 \times 3,5 \times 1,5$ & Knapping tahap lanjut \\
\hline 13 & Panuwunmukti & Calon Kapak Tembeling & $10 \times 5,5 \times 1,5$ & Knapping tahap lanjut \\
\hline 14 & Panuwunmukti & Calon Beliung & $7,5 \times 4 \times 1,5$ & Knapping tahap awal \\
\hline 15 & Panuwunmukti & Calon Beliung & $5,5 \times 4 \times 1$ & $\begin{array}{l}\text { Sawing di bagian proximal } \\
\text { dan Knapping tahap lanjut }\end{array}$ \\
\hline 16 & Rejosari 1 & Calon Beliung & $10 \times 4 \times 2$ & Knapping tahap lanjut \\
\hline 17 & Rejosari 1 & Calon Pahat & $7 \times 2,5 \times 1,5$ & $\begin{array}{l}\text { Sawing dan Knapping } \\
\text { tahap lanjut }\end{array}$ \\
\hline 18 & Senepolor & Calon Beliung & $7,5 \times 6,5 \times 2,5$ & Knapping tahap awal \\
\hline 19 & Sungailembu 2 & Calon Pahat & $15,5 \times 4,5 \times 3,5$ & Knapping \\
\hline 20 & Sungailembu 2 & Calon Beliung & $6,8 \times 3,5 \times 2$ & $\begin{array}{l}\text { Sawing di kedua sisi lateral } \\
\text { dan Knapping }\end{array}$ \\
\hline
\end{tabular}



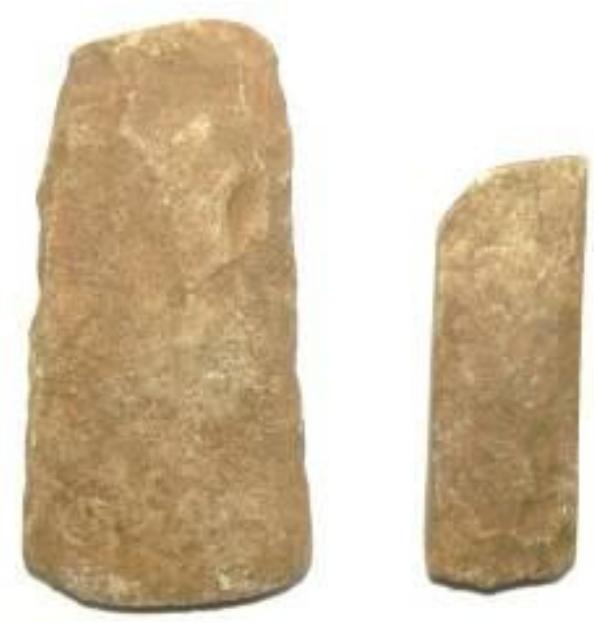

Foto 5. Calon Beliung (Quadrangular Adze) dan Pahat (Gouge) dari Situs Panuwunmukti.

(Sumber: Tim Penelitian 2011)

\section{Beliung}

Beliung (sensu lato) merupakan produk jadi dari proses pembuatan beliung batu yang telah diserpih secara detil dan telah memiliki bidang tajaman. Pada proses pembuatan yang sempurna seluruh permukaan beliung dilakukan pengupaman, sehingga permukaannya sangat halus tanpa meninggalkan jejak penyerpihan, dengan bidang tajaman runcing. Sebuah belincung dan sebuah pahat temuan dari situs Kendenglembu merupakan contoh produk beliung neolitik dari kawasan Banyuwangi Selatan yang telah selesai hingga tahap pengupaman.

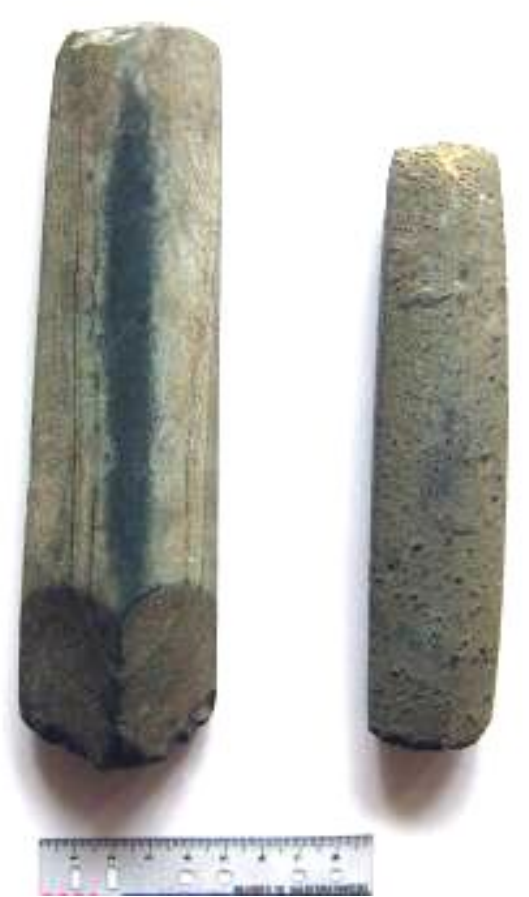

Foto 6. Belincung (Pick Adze) dan Pahat (Gouge) dari Situs Kendenglembu. (Sumber: Tim Penelitian 2009)

Tabel 3. Temuan Beliung dari situs-situs di Banyuwangi Selatan

\begin{tabular}{|c|l|l|c|l|}
\hline No. & \multicolumn{1}{|c|}{ Situs } & \multicolumn{1}{c|}{ Tipologi } & Ukuran $(\mathbf{c m})$ & \multicolumn{1}{c|}{ Jejak Teknologi } \\
\hline 1 & Kendenglembu & Belincung & $19 \times 4,5 \times 2$ & Pengasahan sempurna \\
\hline 2 & Kendenglembu & Pahat & $16 \times 4,5 \times 2$ & Pengasahan sempurna \\
\hline 3 & Panuwunmukti & Beliung Persegi & $9 \times 4,5 \times 1$ & Pengasahan tahap awal \\
\hline 4 & Panuwunmukti & Pahat & $7 \times 2,5 \times 1$ & Pengasahan tahap lanjut \\
\hline
\end{tabular}

\section{Artefak Pembuat}

\section{Batu Pukul}

Batu pukul digolongkan sebagai artefak pembuat (producer), yaitu artefak yang berfungsi untuk menghasilkan artefak lainnya. Biasanya dalam konteks neolitik, artefak batu pukul ditemukan satu paket dengan artefak pembuat lainnya, yaitu batu pelandas dan batu asah. Seluruh tipe artefak tersebut pernah ditemukan oleh Balai Arkeologi Yogyakarta di situs-situs neolitik Banyuwangi Selatan dalam penelitian tahun 2008-2011. 


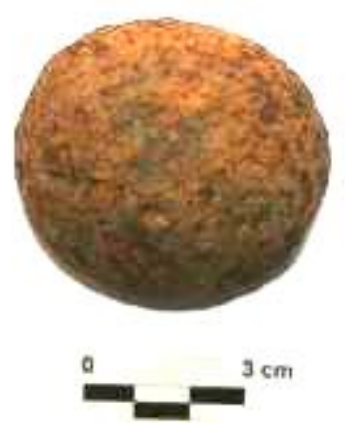

Foto 7. Batu Pukul direct percussion

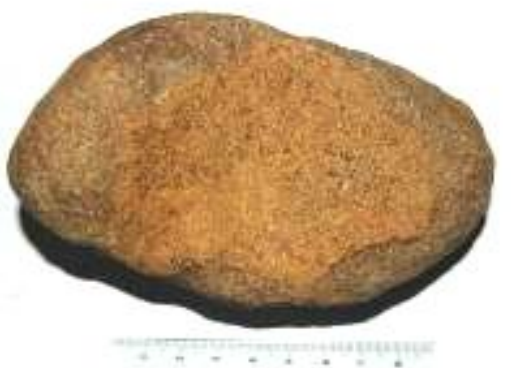

Ada dua jenis artefak batu pukul yang ditemukan berdasarkan fungsinya dalam tahapan pembuatan beliung, yaitu :

1. Batu pukul untuk teknik pemukulan langsung (direct percussion): terbuat dari batu andesit, dengan ciri memiliki luka pukul yang tidak beraturan pada suatu lokasi tertentu, akibat benturan berulang. Batu pukul ini biasanya berbentuk bulat masif.

2. Batu pukul untuk teknik pemukulan tidak langsung (indirect percussion): juga terbuat dari batu andesit, dengan ciri luka berbentuk bulat dan memanjang, akibat benturan dengan alat perantara yang biasanya terbuat dari bahan nonpermanen berupa kayu atau tulang. Batu pukul ini biasanya berbentuk oval atau lonjong.

Foto 8. Batu Pukul indirect percussion

Tabel 4. Temuan batu pukul dari situs-situs di Banyuwangi Selatan

\begin{tabular}{|c|l|c|c|c|c|}
\hline No. & \multicolumn{1}{|c|}{ Situs } & Bahan & Jejak Penggunaan & Bentuk & Ukuran (cm) \\
\hline 1 & Sungai Lembu 1 & Andesit & Direct Percussion & Bulat & $8 \times 6 \times 4,5$ \\
\hline 2 & \multirow{2}{*}{ Sungailembu 2 } & Andesit & Direct Percussion & Bulat & $11 \times 7 \times 5,5$ \\
\cline { 3 - 6 } & & Andesit & Indirect Percussion & Oval & $12 \times 7 \times 3$ \\
\hline 3 & \multirow{2}{*}{ Panuwunmukti } & Andesit & Direct Percussion & Bulat & $5,5 \times 4,5 \times 2$ \\
\cline { 3 - 6 } & & Granit & Direct Percussion & Bulat & $6 \times 5 \times 2,5$ \\
\hline 4 & \multirow{2}{*}{ Sukobumi } & Andesit & Direct Percussion & Bulat & $10 \times 7 \times 4$ \\
\cline { 3 - 6 } & & Andesit & Indirect Percussion & Oval & $12 \times 7 \times 4$ \\
\hline
\end{tabular}

\section{Alat Pemotong Lainnya}

Pada beberapa calon beliung terdapat jejak pemangkasan yang bukan disebabkan oleh teknik knapping, melainkan teknik "gergaji" (sawing) (Bellwood, pers comm). Digunakannya teknik ini mungkin disebabkan oleh karena sulitnya pemangkasan batulempung silikaan yang memiliki sifat dasar batuan sedimen. Batuan sedimen memiliki struktur berlapis, sehingga sangat sulit untuk melakukan pemangkasan (knapping) yang searah dengan pelapisan batuan. Jejak penggunaan teknik pemangkasan sawing pada calon beliung di situs-situs neolitik di Banyuwangi Selatan dapat dengan mudah diamati dengan mata telanjang atau secara makroskopis.
Berdasarkan studi oleh Allchin (1962) terhadap beliung bahu dari Santal Parganas, sebuah situs bengkel neolitik di India, dapat disimpulkan bahwa bagian bahu yang persegi dibuat dengan teknik sawing. Allchin menyarankan bahwa teknik tersebut dengan "gergaji tali" (wire saw) dan bahan abrasif lainnya yang dapat membantu memperlancar pemangkasan, seperti misalnya pasir. Belum ditemukannya "gergaji" yang digunakan dalam teknik sawing di situssitus neolitik Banyuwangi Selatan, memperkuat dugaan bahwa alat tersebut berasal dari bahan organik, sehingga tidak terawetkan dan tidak ditemukan.

\section{Batu Asah}


Artefak batu asah merupakan alat yang digunakan pada saat proses akhir pembuatan beliung batu. Batu asah dicirikan dengan adanya faset-faset pada permukaan, baik pada bagian atas maupun samping. Alat ini digunakan untuk mengupam calon beliung terutama pada bidang tajamannya. Pada proses produksi yang sempurna pengupaman dilakukan pula pada seluruh permukaan beliung, dengan tujuan untuk menghilangkan bekas-bekas pengupaman sehingga menghasilkan permukaan yang halus dan mengkilat.

Berdasarkan hasil penelitian, terdapat dua macam jenis bahan batu asah, yaitu batu andesit dan batu lempung. Keduanya memiliki bekas alur cekungan memanjang selebar ukuran beliung batu. Perbedaan bahan mungkin mengindikasikan perbedaan fungsi masing-masing batu asah tersebut, yaitu untuk mengasah seluruh permukaan beliung dan khusus untuk mengasah bagian tajamannya saja. Selain itu, berdasarkan ukurannya juga terdapat dua macam batu asah, yang berukuran kecil mudah dipindahkan (moveable) dan berukuran besar tidak mudah dipindahkan (non-moveable). Batu asah berukuran besar ditemukan di Situs Sungailembu 1, sedangkan yang berukuran kecil ditemukan di Situs Sungailembu 2 dan Panuwunmukti. Berikut ini adalah tabel temuan batu asah tersebut.

Tabel 5. Temuan batu asah dari situs-situs di Banyuwangi Selatan

\begin{tabular}{|c|c|c|c|c|c|}
\hline No. & Situs & Bahan & Bentuk & Keterangan & Ukuran (cm) \\
\hline 1 & Sungailembu 1 & Andesit & Oval & Masif & $32 \times 13 \times 12$ \\
\hline 2 & Sungailembu 2 & Batulempung & Persegi & Gilap & $7,5 \times 5 \times 1,8$ \\
\hline 3 & Panuwunmukti & Andesit & Persegi & Jejak alur & $14 \times 8 \times 6$ \\
\hline
\end{tabular}

Artefak batu asah yang ditemukan di situs Panuwunmukti pada penelitian tahun 2011, berbahan batu andesit. Ada dua jenis jejak aktifitas pengupaman pada batu asah tersebut, yaitu jejak pengupaman dengan alur, dan jejak pengupaman tanpa alur. Jejak pengupaman dengan alur berfungsi untuk mengupam bagian beliung yang sempit, misalnya bagian lateral dan proximal. Sedangkan jejak pengupaman tanpa alur berfungsi untuk mengupam bagian beliung yang lebar, misalnya bagian dorsal, ventral, maupun kedua sisi tajaman (distal).

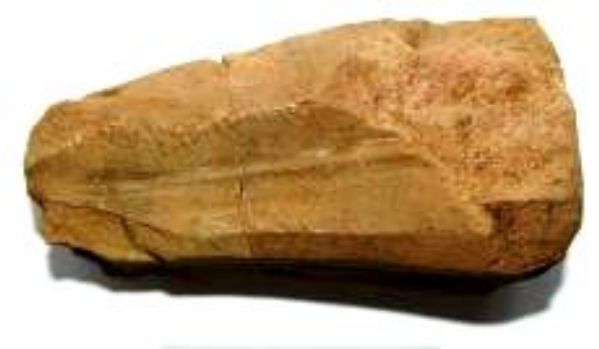

Foto 9. Batu Asah Berbahan Batu Andesit dari Situs Panuwunmukti.

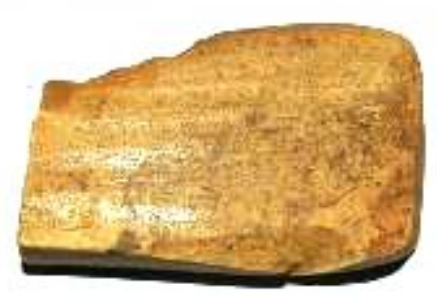

Foto 10. Batulempung dari Situs Sungailembu 2. (Sumber: Tim Penelitian 2009 dan 2011)

\section{Teknik Pembuatan}

Berdasarkan pada hasil pengamatan jejak teknologi yang masih melekat pada produk artefak yang dihasilkan dan temuan alat-alat yang digunakan untuk memproduksi beliung dari situs-situs neolitik di Banyuwangi Selatan, maka dapat direkonstruksi urutan pembuatan artefak beliung batu di kawasan tersebut. Secara umum terdapat tiga tahap utama sejak tahap penyiapan bahan baku hingga tahap penyempurnaan beliung, yaitu:

1. Tahap Penyiapan Bahan Baku 
a. Tahap penambangan bahan baku di lokasi singkapan batuan

b. Tahap Penyiapan bahan baku menjadi batu inti

c. Transportasi batu inti dari situs penambangan ke situs yang membutuhkan

2. Tahap Pembuatan Beliung

a. Bentuk dasar calon beliung, dengan pemangkasan langsung (direct percussion), sering kali gagal

b. Bentuk dasar calon beliung yang kecil dan ramping digunakan metode gergaji (sawing technique). Hal ini disebabkan karena sulitnya pemangkasan pada batuan sedimen lempung silikaan yang berlapis, sehingga rentan gagal.

c. Pemangkasan detail, dengan pemangkasan tidak langsung (indirect percussion) dari bagian pinggir (lateral) ke bagian tengah (medial), ada kalanya gagal.

3. Tahap Penyempurnaan Beliung

a. Pengupaman pada keempat muka calon beliung, kecuali bagian pangkal (proximal), kadang gagal

b. Penajaman bagian tajaman (distal)

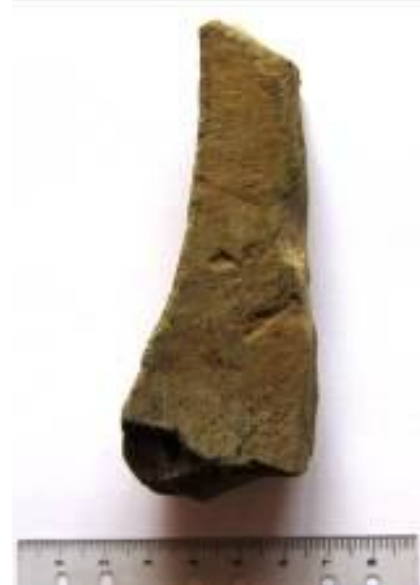

Foto 11. Sawing Technique bagian dorsal/ventral.

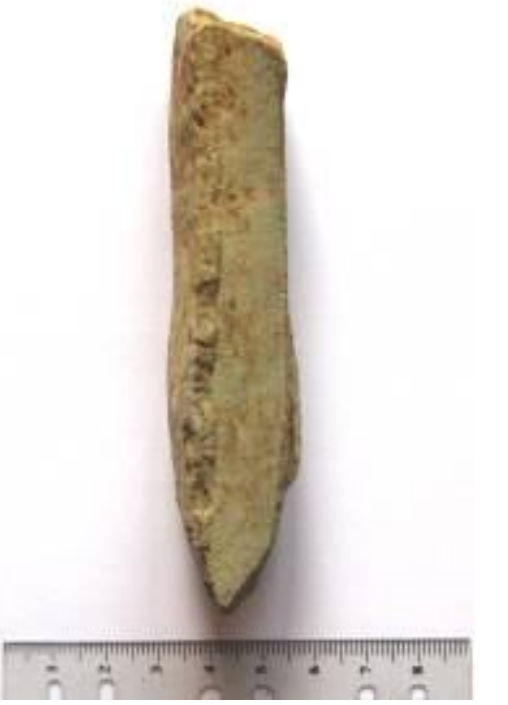

Foto 12. lateral dari Situs Panuwunmukti. (Sumber: Tim Penelitian 2008)

Hal yang istimewa dari teknologi pembuatan beliung batu dari situs-situs neolitik di kawasan Banyuwangi Selatan adalah penggunaan teknik gergaji (sawing tecnique). Selain di Indonesia, teknik ini juga ditemukan di Kulai Kua, Bien Hoa (Vietnam), Samrong Sen, (Kamboja) dan lle Cave, Palawan, (Filipina), situs-situs yang mewakili neolitik Asia Tenggara Daratan dan Kepulauan (Heng 2007 dan Pawlik 2007). Pada umumnya, teknik sawing digunakan dalam pembuatan beliung bahu dan beliung tangga yang memiliki bentuk berundak pada bagian proximal. Pada kedua tipe beliung tersebut, memiliki bentuk sudut yang sangat tajam dan presisi, sehingga tidak mungkin dibentuk dengan menggunakan teknik penyerpihan (knapping). Heng (2007) telah melakukan pengamatan makroskopis dan analisis mikroskopis terhadap kasus serupa pada kumpulan beliung neolitik dari Kamboja, hasilnya diketahui bahwa jejak striasi pada beliung tersebut sangat mungkin disebabkan oleh penggunaan sawing technique.

Roger Duff (1970) dalam publikasinya mengenai "Stone Adzes of Southeast Asia" juga mencatat ada jejak sawing pada beliung bahu dan pahat dari situs Samrong Sen di Dataran Mansuy, Kamboja yang berasal dari periode neolitik akhir. Duff juga mencatat 
bahwa teknologi pada periode neolitik akhir ditandai dengan penguasaan skill yang tinggi pada pembuatan alat batu, meliputi teknik sawing, drilling yang kemudian berkembang menjadi doublecrater drilling dan tubular bore technique. Teknik yang terakhir ini dapat kita jumpai penggunaannya pada komplek situs perbengkelan gelang batu Tipar-Ponjen di Purbalingga (Jawa Tengah). Duff juga berhipotesis bahwa teknologi ini dapat menyebar luas yang berasal dari suatu daerah di Cina Selatan (Duff 1970).

\section{TEKNOLOGI BELIUNG BATU NEOLITIK BANYUWANGI SELATAN DALAM PERSPEKTIF KAWASAN}

Pembicaraan mengenai teknologi beliung batu neolitik dalam perspektif kawasan tidak terlepas dari wacana asal usul dan persebaran teknologi ini. Pionir studi tentang proses penyebaran beliung batu di Asia Tenggara adalah Robert Heine-Geldern (1932) seorang sarjana
Austria. Heine-Geldern mengkaitkan antara tiga kelompok budaya neolitik berdasarkan tipe alat batu yang dihasilkan, dengan tiga rumpun bahasa yang digunakan di Asia Tenggara Daratan dan Kepulauan, yaitu:

1. Walzenbeilkuture, budaya kapak lonjong (Round Axe Culture) persebarannya setara dengan populasi penutur rumpun bahasa Papua.

2. Schulterbeilkultur, budaya beliung bahu (Shouldered Adze Culture) persebarannya setara dengan masyarakat penutur bahasa Austroasiatik di Asia Tenggara Daratan.

3. Vierkantbeikultur, budaya beliung persegi (Quadrangular Adze Culture) persebarannya setara dengan masyarakat penutur bahasa Austronesia di Asia Tenggara Kepulauan (Heine-Geldern 1932).

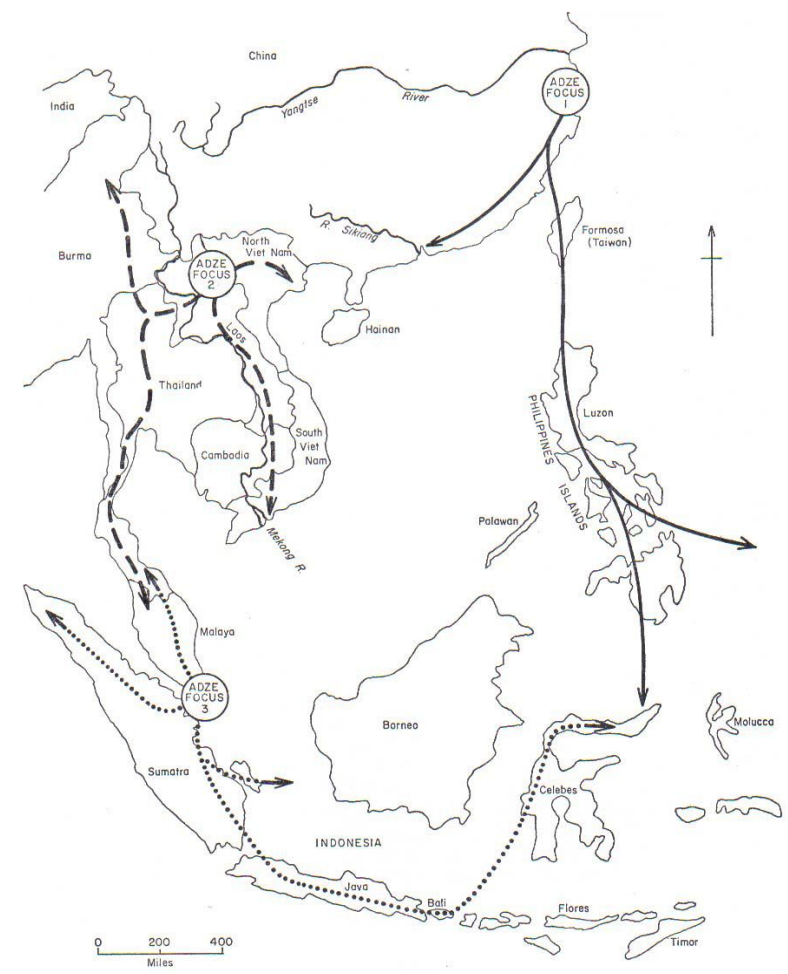

Peta 3. Peta Tiga Fokus Asal-usul Persebaran Beliung di Asia Tenggara.

(Sumber: Duff 1970)

Setelah Heine-Geldern, Roger Duff (1970) melakukan studi yang lebih detail dan mendalam mengenai distribusi beliung batu di Asia Tenggara. Walaupun demikian, studinya berdasarkan pada koleksi yang tidak memiliki catatan stratigrafi maupun posisi lapisan budaya yang jelas, karena kebanyakan koleksi tersebut berasal dari berbagai museum di beberapa negara di Asia Tenggara. Duff mengklasifikasikan tipologi beliung dan mengadaptasikan 
teori Heine-Geldern mengenai penyebaran beliung dan menambahkan beberapa penemuan dan hipotesis baru. Berdasarkan pada studi tipologi beliung tersebut, dikemukakan tiga zona utama penyebaran:

1. Fokus 1 meliputi Cina Selatan, Taiwan dan Filipina. Fokus 1 lokasi asal usul beliung persegi (Quadrangular Adze) yang kemudian menyebar ke seluruh Asia Tenggara.

2. Fokus 2 mencakup Birma, Kamboja, Laos, Vietnam dan Thailand Utara. Fokus 2 adalah tempat perkembangan lokal beliung bahu (Shouldered Adze), yang kemudian menyebar ke seluruh Indocina, Thailand, Birma dan beberapa tempat di India.

3. Fokus 3 berada di Thailand Selatan, Malaysia dan Indonesia. Fokus 3 kemungkinan adalah tempat asal usul belincung (Pick Adze) yang sangat umum ditemukan di Malaysia, Indonesia, dan Thailand Selatan (Duff, 1970).

Sangat menarik bahwa di kompleks situs-situs perbengkelan neolitik di Banyuwangi Selatan setidaknya ditemukan empat tipe beliung batu, yaitu: beliung persegi (quadrangular adze), belincung (pick adze), kapak Tembeling, dan pahat (gouge). Padahal kita ketahui bahwa budaya beliung persegi bersama dengan teknologi sawing technique berasal dari Cina Selatan. Kemudian pahat sangat populer di Asia Tenggara Daratan tempat asal usul beliung bahu. Sedangkan belincung dan kapak tembeling diperkirakan berasal dari Indonesia bagian barat khususnya Sumatera dan Semenanjung Malaysia (lihat Duff 1970). Berdasarkan kelengkapan variasi tipologi beliung situs-situs perbengkelan neolitik Banyuwangi Selatan, maka dapat disimpulkan bahwa situs-situs di kawasan tersebut memiliki posisi yang sangat penting dalam peta prasejarah di Asia Tenggara dan membuktikan keterkaitan di antara mereka secara kultural.

Secara diakronis, keberadaan sawing technique yang diperkirakan berasal dari periode neolitik akhir mendukung hipotesis posisi kronologis keberadaan situs-situs perbengkelan neolitik di Banyuwangi Selatan. Sampai saat ini baru satu pertanggalan yang dihasilkan dari situs di kawasan tersebut, yaitu $1.332 \pm 35$ BP yang berasal dari layer budaya neolitik di situs Rejosari 1 (Noerwidi 2009). Padahal secara kultural kompleks situs neolitik di Banyuwangi Selatan juga menghasilkan gerabah slip merah yang menjadi ciri penanda periode neolitik awal di Indonesia bagian timur, seperti yang ditemukan di situs Kalumpang (Sulawesi Barat) yang berumur 3.500 BP (Simanjuntak 2006). Analisis pertanggalan yang lebih presisi dari kompleks situs neolitik di Banyuwangi Selatan di masa yang akan datang sangat diperlukan guna menjawab permasalahan kronologi ini.

\section{PENUTUP}

Berdasarkan tulisan ini, maka telah diketahui bahwa manfaat studi chaîne opératoire adalah guna mengungkap aspek-aspek teknologi yang berkaitan dengan proses pembuatan beliung batu dari situs-situs perbengkelan neolitik di kawasan Banyuwangi Selatan. Studi ini diharapkan mampu menambah pandangan mengenai teknologi pembuatan alat batu pada masa neolitik dan sedikit gambaran aspek sosial kehidupan masyarakat penutur bahasa Austronesia di Indonesia.

Di masa yang akan datang diharapkan dilakukan studi chaîne opératoire yang lebih detail dan lengkap mengenai aspek-aspek teknologi neolitik dari situs-situs perbengkelan di kawasan Banyuwangi Selatan maupun dari situs lainnya di Indonesia. Analisis mikroskopis terhadap jejak teknologi diharapkan mampu melengkapi hasil pengamatan makroskopis yang telah dilakukan dalam penelitian ini. Selanjutnya, arkeologi eksperimental dalam studi chaîne opératoire juga sangat diperlukan, seperti misalnya untuk mengungkapkan "wire saw" yang digunakan dalam teknik pemotongan "sawing technique" seperti yang ditemukan dalam penelitian ini. 
Akhirnya kita ketahui bahwa data arkeologis budaya neolitik dari situs-situs neolitik di Banyuwangi Selatan yang dianalisis dalam penelitian ini memiliki banyak kesamaan dengan produk budaya neolitik dari di Indonesia, seperti misalnya situs-situs Kalumpang di Sulawesi Barat dan situs-situs sejenis lainnya di Asia Tenggara Daratan dan Kepulauan. Beberapa kesamaan tersebut khususnya terdapat pada teknologi pembuatan beliung batu, seperti yang dibahas dalam tulisan ini. Beberapa kesamaan pada teknologi pembuatan alat batu antara lain adalah :

1. Penggunaan bahan dasar batuan sedimen silikaan

2. Teknologi pengerjaan; dengan teknik sawing, knapping dan polishing

3. Tipologi produk beliung batu yang dihasilkan

Berdasarkan pada pada beberapa bukti tersebut, dapat diketahui bahwa terdapat hubungan yang cukup erat antara budaya neolitik Austronesia di Banyuwangi Selatan dengan budaya sejenis di Asia Tenggara pada umumnya. Hal ini membuka permasalahan baru mengenai hipotesis kronologi budaya neolitik dan persebaran masyarakat penutur bahasa Austronesia di Indonesia.

\section{UCAPAN TERIMAKASIH}

Penulis

mengucapkan penghargaan yang tinggi atas kerjasama seluruh anggota tim Balai Arkeologi Yogyakarta yang terlibat dalam penelitian situs permukiman neolitik Austronesia di Banyuwangi, yaitu: Goenadi Nh, Harry Widianto, Priyatno H.S, Gunadi Ks, Indah Asikin, Siswanto, Tedy Setiadi, Mujiyono, Slamet Widodo, Didik Santosa, Bakrun, Ngadimin, Mujiyana, dan Sugeng. Ucapan terima kasih juga disampaikan kepada Agus T.H, dan Muasomah Sidik dari Jurusan Arkeologi FIB UGM, Dinas Kebudayaan dan Pariwisata Kab. Banyuwangi, PTPN XII Wilayah I Kendenglembu, Kalirejo, Sumberjambe, dan Sungailembu, KPH Banyuwangi Selatan, serta seluruh masyarakat Banyuwangi Selatan yang telah berpartisipasi dalam penelitian ini. 


\section{DAFTAR PUSTAKA}

Allchin, F.R., 1962. "The Neolithic Stone Industry of the Santal Parganas". Dalam Bulletin of the School of Oriental and African Studies Vol. 25, No. 1/3. London: University of London. HIm. 306-330.

Bar-Yosef, Ofer and Philip Van Peer. 2009. "The Chaine Operatoire Approach in Middle Paleolithic Archaeology". Dalam Current Anthropology 50 (1). HIm. 103-131.

Bellwood, Peter. 2000. Prasejarah Kepulauan Indo-Malaysia. Edisi revisi. Jakarta: PT.Gramedia Pustaka Utama.

Duff, Roger. 1970. "Stone adzes of Southeast Asia". Dalam Canterbury Museum Bulletin No. 3. Christchurch: New Zealand. HIm. 1-156

Grace, Roger. 1997. "The Chaîne Opératoire Approach to Lithic Analysis". Dalam Stone Age Reference Collection. Oslo: Institute of Archaeology, University of Oslo. http://intarch.ac.uk/journal/issue2/grace toc.html

Hantoro, Nugroho Widi. 1995. "Calon Beliung Situs Ngrijang Sengon di Punung Pacitan: Tinjauan Teknologis Berdasarkan Data Permukaan". Skripsi Sarjana. Jurusan Arkeologi Fakultas Sastra Universitas Gadjah Mada.

Heekeren, H.R. van. 1972. "The Stone Age of Indonesia". Verhandelingen van het Koninklijk Instituut voor Tall-, Land-, en Volkenkunde, 61. Revised Edition. Hague: Martinus Nijhoff.

Heine-Geldern, Robert von. 1932. "Urheimat und früheste Wanderungen der Austronesier". Dalam Anthropos (XXVII). HIm. 543-619.

Heng, Sophady. 2007. "A Study of Polished Stone Tools from Samrong Sen, Cambodia: The French Museum Collections". Tesis Pasca Sarjana. Paris: MNHN.

Heydar, Muhammad. 1989. "Calon Beliung Situs Teleng di Punung, Pacitan: Analisis Teknologi Berdasar Data Temuan Permukaan". Skripsi Sarjana. Jurusan Arkeologi Fakultas Sastra Universitas Gadjah Mada.

Noerwidi, Sofwan. 2009. "Archaeological Research at Kendenglembu, East Java". Dalam Bulletin of Indo-Pacific Prehistory Association 29. HIm. 26-32.

2013. "Analisis Site Catchment Situs-situs Permukiman Neolitik di Banyuwangi Selatan". Dalam Berkala Arkeologi Vol. 33 No. 1 Mei. Yogyakarta: Balai Arkeologi Yogyakarta.

Pawlik, Alfred. 2007. "Analysis of Two Polished Stone Adzes from Ille Cave at El Nido, Palawan Island, Philippines". Tidak diterbitkan.

Schiffer, M.B. 1976. Behavioral Archaeology. New York Academic Press.

Simanjuntak, Truman. 1984. "Penelitian Situs Tipar Ponjen, Purbalingga, Jawa Tengah". Laporan Penelitian Arkeologi. Balai Arkeologi Yogyakarta. 
2006. "Austronesian in Sulawesi: Its Origin, Diaspora, and Living Tradition". Dalam Truman Simanjuntak (ed.). Austronesian in Sulawesi. Jakarta: CPAS. HIm. 215-251.

2007. "Kata Pengantar". Dalam Hubert Forestier. Ribuan Gunung, Ribuan Alat Batu: Prasejarah Song Keplek, Gunungsewu, Jawa Timur. Jakarta: KPG. HIm. 15-17.

Poesponegoro, Marwati Djoened, dan Nugroho Notosusanto. 2008. Sejarah Nasional Indonesia I: Zaman Prasejarah di Indonesia. Jakarta: Balai Pustaka

Soressi, Marie and Jean-Michel Geneste. 2011. "Special Issue: Reduction Sequence, Chaîne Opératoire, and Other Methods: The Epistemologies of Different Approaches to Lithic Analysis; The History and Efficacy of the Chaîne Opératoire Approach to Lithic Analysis: Studying Techniques to Reveal Past Societies in an Evolutionary Perspective". Dalam PaleoAnthropology 336. HIm. 334-350.

Spriggs, Matthew. 1989. "The Dating of the Island Southeast Asian Neolithic: an Attempt at Chronometric Hygiene and Linguistic Correlation". Dalam Antiquity 63. HIm. 587613.

2000. "Out of Asia: The Spread of Southeast Asian Pleistocene and Neolithic Maritime Culture in Island Southeast Asia and Western Pacific". Dalam Sue O'Connor dan Peter Veth (eds.). East of Wallace's Line, Studies of Past and Present Maritime Culture of the Indo-Pacific Region. Rotterdam: A.A. Balkema. HIm. 51-76.

Tanudirdjo, Daud Aris. 1991. "Some Behavioral Aspect of the Bomo-Teleng Stone Adze Workshop Site in East Java". Tesis Pasca Sarjana. ANU, Canberra.

2003. "Warisan Budaya untuk Semua, Arah Kebijakan Pengelolaan Warisan Budaya Indonesia di Masa Mendatang". Makalah disampaikan dalam Kongres Kebudayaan V di Bukit Tinggi.

Tim Penelitian. 2008. "Karakter Budaya dan Kronologi Hunian Situs Kendenglembu (Tahap I)". Laporan Penelitian Arkeologi. Balai Arkeologi Yogyakarta.

2009. "Karakter Budaya dan Kronologi Hunian Situs Kendenglembu (Tahap II): Survey Sepanjang Aliran Sungai Lele, Sungai Lembu dan Sungai Karangtambak". Laporan Penelitian Arkeologi. Balai Arkeologi Yogyakarta.

2010. "Karakter Budaya dan Kronologi Hunian Situs Kendenglembu (Tahap III): Ekskavasi Situs Sukobumi”. Laporan Penelitian Arkeologi. Balai Arkeologi Yogyakarta

. 2011. "Karakter Budaya dan Kronologi Hunian Situs Kendenglembu (Tahap IV): Ekskavasi Situs Panuwunmukti dan Situs Kendenglembu". Laporan Penelitian Arkeologi. Balai Arkeologi Yogyakarta.

Widianto, Harry. 1998. "Ekskavasi Ngrijangan: Karakter Teknologis dan Tipologis Artefak pada Perbengkelan Neolitik di Punung, Pacitan". Berita Penelitian Arkeologi No. 02. Yogyakarta: Balai Arkeologi Yogyakarta. 
